\title{
ALIMENTOS ENTRE CONVIVIENTES: DE DEBER NATURAL A DEBER CONSTITUCIONAL. UNA LECTURA DIFERENTE.
}

\author{
FOOD BETWEEN COHABITANTS: \\ FROM NATURAL DUTY TO CONSTITUTIONAL \\ DUTY. A DIFFERENT READING
}

YuRI Vega Mere*

* Profesor Honorario de la Universidad Católica Santa María (Arequipa). Socio Senior del estudio Muñiz. Maestría en la Universidad Particular de San Martín de Porres (2009-2010). - Especialización en Disciplinas Bancarias de la Facultad de Economía en Universita degli Studi di Siena, Italia (1993). - Abogado de la Universidad Nacional Mayor de San Marcos (1992).yvega@munizlaw.com 


\title{
ALIMENTOS ENTRE CONVIVIENTES: DE DEBER NATURAL A DEBER CONSTITUCIONAL. UNA LECTURA DIFERENTE.
}

\author{
FOOD BETWEEN COHABITANTS: FROM NATURAL \\ DUTY TO CONSTITUTIONAL DUTY. A DIFFERENT READING
}

Yuri Vega Mere

\begin{abstract}
Resumen:
En el presente artículo el autor desarrolla la regulación que le corresponde a los "alimentos" entre los convivientes y las inconsistencias plasmadas en nuestro ordenamiento legal. Sostiene que ni el constituyente de 1979 ni el legislador de nuestra ley civil de 1984 quisieron reconocer un estatus pleno de familia a las parejas de hecho y que ello resulta un absurdo dado que la concesión de un régimen patrimonial no caía en el vacío ni fue consagrado para una entelequia o un ente etéreo: fue concebido para una pareja no casada que era (y es) abiertamente una familia, las más de las veces integrada por los concubinos y por sus descendientes. Plantea una interrogante interesante que irá esbozando en el presente artículo, que es la siguiente ¿cómo afectaba esta restricción del régimen normativo a las uniones de hecho?.
\end{abstract}

\section{Palabras clave:}

Alimentos, convivientes, deberes, familia, parejas de hecho

\begin{abstract}
:
In this article the author develops the regulation that corresponds to the "food" among the cohabitants and the inconsistencies reflected in our legal system. He argues that neither the constituent of 1979 nor the legislator of our civil law of 1984 wanted to recognize a full family status for unmarried couples and that this is absurd given that the granting of a patrimonial regime did not fall into a vacuum nor was it consecrated for an entelechy or an ethereal being: it was conceived for an unmarried couple that was (and is) openly a family, most of the times integrated by the concubines and by their descendants. It raises an interesting question that will be outlined in the present article, which is the following: how did this restriction of the normative regime affect de facto unions?
\end{abstract}

\section{Key words:}

Food, cohabitants, duties, family, de facto couples

\section{1.-Preliminares}

A pesar de lo que se pueda decir, la doctrina y la jurisprudencia no han hecho mayores esfuerzos por dar una opinión definitiva o, al menos, suficientemente ponderada y sustentada, sobre el deber (y derecho) alimentario entre concubinos.

De alguna manera la doctrina y las Cortes han estado condicionadas por el favor matrimonii arraigado en la legislación ordinaria y, por qué no, por el principio de promoción del matrimonio que encontramos en la actual Constitución.

Anecdóticamente, ha sido la incorporación de los principios constitucionales de protección de la familia y de fomento del matrimonio los que podrían haber sido utilizados, en mi concepto, para llegar a una visión stronger, si se me permite el uso de una palabra inglesa, ya que percibo una cierta debilidad o tibieza en la asunción del deber alimentario entre convivientes como uno de orden "natural". 
Y es, precisamente, por ello, que antes de llegar a una justificación de una naturaleza jurídica diferente (o, mejor dicho, del legal support que tienen los alimentos entre la pareja no casada) me gustaría pasar revista a los antecedentes y al estado actual de las cosas.

1. La visión estrecha y patrimonialista de la unión de hecho: un rápido survey a los debates de la Asamblea Constituyente de 1978-1979 y al Código Civil dentro del contexto de su promulgación

Para empezar, recordemos que el artículo 5 de la Constitución de 1979 rezaba:

El Estado protege el matrimonio y la familia como sociedad natural e institución fundamental de la Nación.

Las formas de matrimonio y las causas de separación y disolución son reguladas por la ley. La ley señala las condiciones para establecer el patrimonio familiar inembargable, inalienable y transmisible por herencia.

La Constitución de 1979 centró la tutela de la familia basada en el matrimonio.

El modelo de la familia matrimonial (que además se encontraba recogido en diversos instrumentos internacionales sobre derechos humanos y derechos civiles y políticos existentes hasta ese momento ${ }^{1}$ ) respondía a la tradición y a los valores $-y$ prejuicios- que se hicieron presentes en los debates para la redacción de la Constitución de aquel año.

La preferencia por el matrimonio se explicaba, entre otras razones por: (i) el carácter estable y cierto de la relación por la forma y ceremonia que rodea la celebración desde los actos previos a dicho momento en la que además interviene el Estado a través de un funcionario público "publificando" el acto solemne, esto es, otorgándole notas de Derecho público; (ii) la -en principio- indisolubilidad del vínculo; (iii) la mejor y más sencilla determinación de las relaciones que se derivan del matrimonio entre los esposos, los hijos y los familiares de los cónyuges con éstos y su descendencia, que no son otra cosa que el surgimiento inmediato de efectos legales entre los nombrados; (iv) el ser el espacio legitimador de las relaciones sexuales; (v) el ser soporte de una serie de presunciones de paternidad y maternidad (que la ciencia luego pondría en cuestión); etc.

Las uniones no matrimoniales no eran bien vistas. Se desconfiaba de ellas y se las enjuiciaba como moralmente inaceptable. Se las miraba con reserva por su carácter (aparentemente) precario, efímero, tímido, etc. y por intentar legitimar relaciones íntimas entre dos personas no casadas.

Vega (2005) sostiene que "Por esa razón, en la discusión sobre el concubinato durante los debates de la Asamblea Constituyente de 1978-1979, además de limitarse la débil protección al concubinato propio o perfecto, también se redujo todo intento de recepción del mismo a aspectos puramente patrimoniales.

Cuando la referida Asamblea Constituyente discutía lo que fue el artículo 9 de la Constitución de 1979, en un primer intento se propuso aplicar al concubinato el régimen de la sociedad conyugal y no el de la sociedad de gananciales, con lo cual se hubiere equiparado la unión de hecho al matrimonio como lo hizo notar el constituyente Alayza Grundy. Pero ello no prosperó ni podía prosperar bajo la visión estrictamente matrimonialista de la familia.

Si se revisa el Diario de Debates de la Comisión Principal de Constitución de la Asamblea Constituyente 1978-1979, Lima, Publicación Oficial, Tomo I, pp. 316 y 317, en efecto, se puede advertir que el constituyente Andrés Aramburú Menchaca alude a que en el proyecto del artículo relativo a la protección de la familia y el matrimonio se recogía los preceptos de las declaraciomnes y pacto sobre derechos humanos, razón por la cual no hubo mayor fundamentación. 
La consigna de imponer un régimen comunitario a los convivientes obedeció, en términos generales, a la difundida idea de que los concubinos varones solían adquirir bienes comunes a su nombre y luego abandonar a la pareja sin dividir o distribuir el patrimonio adquirido con el esfuerzo de ambos. Es, curiosamente, el mismo argumento que utilizaría Cornejo Chávez (1999) cuando explicó la implantación de la comunidad de bienes de la pareja no matrimonial que finalmente sustentó -en su momento, como veremos- la redacción del artículo 326 del Código civil.

En los mencionados debates hubo posiciones radicalmente opuestas a dar a la unión de hecho un tratamiento similar al del matrimonio, privilegiándose la dimensión patrimonial de los concubinatos como lo hizo notar Javier Valle Riestra cuando señaló que: "Estamos aquí legislando para una posibilidad, que parece no coincidir mucho con la peruana; estamos hablando del aspecto no humano, sino del aspecto económico de los concubinatos ... (la negrita es mía).

Pese a ello, se impuso el punto de vista defendido por Cornejo Chávez cuando sostuvo que no se quería establecer un matrimonio de segundo grado y que la propuesta en discusión se reducía a los efectos patrimoniales sin incorporar los personales, al menos en el momento (es decir, en la época) de la discusión acogiendo la necesidad de que se precise que la comunidad de bienes queda sujeta a la sociedad de gananciales y no a la conyugal que advirtiera el constituyente conservador Alayza Grundy.

De esa manera se consagró un régimen dedicado única y exclusivamente a las relaciones patrimoniales entre los concubinos, limitaciones que fueron agravadas por el Código civil.

Finalmente, el texto aprobado por dicha Constitución fue:

"Artículo 9.- La unión estable de un varón y una mujer, libres de impedimento matrimonial, que forman un hogar de hecho por el tiempo y en las condiciones que señala la ley, da lugar a una sociedad de bienes que se sujeta al régimen de la sociedad de gananciales en cuanto es aplicable."

El Código civil perpetuó los valores y prejuicios del constituyente de 1979 en materia de concubinato. Su art. 326, aún vigente con la misma redacción original, reza:

La unión de hecho, voluntariamente realizada y mantenida por un varón y una mujer, libres de impedimento matrimonial, para alcanzar finalidades y cumplir deberes semejantes a los del matrimonio, origina una sociedad de bienes que se sujeta al régimen de la sociedad de gananciales, en cuanto le fuere aplicable, siempre que dicha unión haya durado por lo menos dos años continuos. La posesión constante de estado a partir de fecha aproximada puede probarse con cualquiera de los medios admitidos por la ley procesal, siempre que exista un principio de prueba escrita. La unión de hecho termina por muerte, ausencia, mutuo acuerdo o decisión unilateral. En este último caso, el juez puede conceder, a elección del abandonado, una cantidad de dinero por concepto de indemnización o una pensión de alimentos, además de los derechos que le correspondan de conformidad con el régimen de la sociedad de gananciales.

Tratándose de una unión de hecho que no reúna las condiciones señaladas en este artículo, el interesado tiene expedita, en su caso, la acción de enriquecimiento indebido.

El legislador ordinario no tuvo como intención instaurar un régimen de protección al concubinato. Su intención fue lograr su paulatina disminución y eventual desaparición y no crear un matrimonio de segunda clase (Cornejo Chavez, 1999, pp.66) reduciendo la protección de las parejas no a aspectos económicos, tal como lo sostienen Arias Schreiber, M., Arias Schereiber, A. y Plácido (2002) En la Exposición de Motivos del art. 326 se dijo claramente ello. Es más, Cornejo Chávez propuso que el plazo para el surgimiento de la sociedad de bienes fuera de cinco años².

2 Ver, CORNEJO CHÁVEZ, HÉCTOR, Exposición de Motivos y comentarios al Libro de Familia del Código civil de 1984 , en Código civil, Exposición de Motivos y comentarios, Comisión Encargada del estudio y revisión del Código civil, Compiladora: Delia Revoredo, Lima, 1988, IV, pp. 473 a 479. 


\section{La referencia a los "alimentos" entre convivientes y las inconsistencias del Código civil (y de alguna sentencia del Supremo Tribunal)}

Resulta más que evidente que ni el constituyente de 1979 ni el legislador de 1984 quisieron reconocer un estatus pleno de familia a las parejas de hecho.

Ello resulta absurdo dado que la concesión de un régimen patrimonial no caía en el vacío ni fue consagrado para una entelequia o un ente etéreo: fue concebido para una pareja no casada que era (y es) abiertamente una familia, las más de las veces integrada por los concubinos y por sus descendientes.

Pero entonces, ¿cómo afectaba esta restricción del régimen normativo a las uniones de hecho? Lo que se derivaba como efecto es que se cercenaba la posibilidad (al menos en sede judicial) de exigir la observancia de deberes personales. Y ello era otro dislate si nos referimos, por ejemplo, al deber de fidelidad. Si la propia configuración de la institución alude a la unión de varón y mujer, la doctrina ha dicho hasta el hartazgo que debe ser una unión monogámica. Ello implica que no es posible que ninguno de los convivientes mantenga una relación paralela, esto es, que no sea leal.

Las parejas no casadas se unen para forjar una comunidad de vida. El artículo 326 del Código civil no pudo dejar de señalar que la unión de hecho se forma para alcanzar finalidades y cumplir deberes semejantes a los del matrimonio.

Por ello, Bigio (1992) considera que el comportamiento de la pareja deberá ceñirse a las pautas generales que el Código señala respecto de las relaciones personales entre los cónyuges. Ello implicará, en línea de principio, fidelidad y asistencia mutuas (artículo 288).

Los concubinos también tienen el derecho y el deber de participar en el gobierno del hogar y a decidir los temas atinentes a la economía del hogar.

Si los concubinos establecen una relación marital estable no encuentro escollo para entender que la pareja se debe asistencia en la medida que su relación se forja para alcanzar finalidades y cumplir deberes semejantes a los del matrimonio. Y el socorro mutuo es uno de dichos deberes.

Si nos detenemos a analizar el caso concreto y particular del deber alimentario, es probable que lleguemos a la primera de tantas contradicciones pues dado que no existe norma o mandato especial, la conclusión es que los concubinos no están obligados a prestarse alimentos mientras conviven. Además, tampoco se encuentran comprendidos entre los obligados en el numeral 474 del Código civil.

La segunda contradicción que advierto es que la propia ley reconoce alimentos en caso de conclusión de la unión paramatrimonial cuando termina por la decisión unilateral de uno de los consortes, que abandona al otro. Esto es, ya no entre concubinos sino entre "ex" convivientes.

En una curiosa sentencia de nuestra Corte Suprema del 7 de junio 1993, se señala que el cese de la unión de hecho no sólo consiste en la terminación de la convivencia bajo un mismo techo sino, aun si ésta persiste, cuando uno de los concubinos se sustrae intencional y deliberadamente a las obligaciones emergentes de la unión de hecho. La Corte señala que, de acuerdo al artículo 326 del Código, la decisión unilateral de uno de los convivientes de terminar la unión faculta al juez a conceder, a elección del abandonado, una indemnización o una pensión de alimentos. En el caso resuelto la demandante exigía que el demandado la acudiera con una pensión alimenticia por haber terminado la unión de hecho de más de treinta años ininterrumpidos. El demandado, al salir a juicio, sostuvo que no era verdad que la unión hubiere cesado por cuanto seguía viviendo junto a la actora, en el mismo inmueble. Frente a tal alegación, la Corte entendió que debía considerarse como cesación de la unión la sustracción a los deberes emergentes de la misma (que no precisa, 
en nada) por parte de uno de los convivientes al margen que siguieran viviendo juntos y que nada le impedía señalar una pensión fija y permanente (sic) no obstante que el demandado pudiera estar acudiendo con una suma de dinero que resultaba exigua para subvenir las necesidades del otro. La Corte falló que el demandado asistiera a la actora con una pensión alimenticia adelantada del veinte por ciento de su haber líquido.

Esta sentencia contiene una serie de aspectos que vale la pena analizar. En primer lugar, el Supremo Tribunal alude a "deberes emergentes" de la unión de hecho que no detalla. Si quisiéramos forzar una interpretación no cabría otra que entender que se refiere a la asistencia recíproca que se deben los convivientes, a los cuales hemos considerado aplicable el artículo 288 del Código civil. En segundo lugar, si la Corte hubiera tenido en cuenta que la asistencia constituye un deber de mayor cobertura que la obligación alimentaria, podría haber condenado al conviviente al pago de tal pensión sin incurrir en la ficción de dar por terminada la unión de hecho.

El artículo 326 del Código civil no autoriza a incluir como cese de un concubinato el que uno de los miembros de la pareja se sustraiga a sus deberes. La Corte, simple y llanamente, atendiendo al comportamiento que había observado el demandado por más de treinta años, debió derivar que el deber de asistencia que asumió voluntariamente había sido incumplido a partir de un cierto momento, pero también debió deducir de tal comportamiento que su voluntad fue hacerse cargo de la situación económica de la actora y, por ende, obligarlo al cumplimiento del tanta vences mencionado deber de socorro. Pero como su fallo concluye en la fijación de una pensión alimenticia, no pudo escapar al condicionamiento impuesto por el artículo 474 del mismo Código que no prevé la prestación alimentaria para los convivientes more uxorio. A fin de encontrar una solución, que se amparase en el propio artículo 326, decidió considerar terminada la unión de hecho aun cuando siguiera habiendo comunidad de techo y no sabemos si de lecho.

Comencemos por lo menos complejo. Si la unión de hecho termina por muerte (natural, cerebral o presunta), el tema parece no crear mayores problemas, más aun cuando hoy en día el conviviente sobreviniente tiene derechos sucesorios para lo cual es necesario que la unión no haya terminado antes del momento de la muerte. Si, en cambio, concluye por decisión acordada, es previsible que los interesados pongan fin al régimen de comunidad de bienes que la ley les impone.

Mayor dificultad presenta la solución prevista en el numeral 326 cuando la cohabitación cesa por decisión unilateral de uno de los convivientes. En este caso, la ley establece que, sin perjuicio de los derechos que resulten de la aplicación de las normas sobre el régimen de la sociedad de gananciales, el concubino abandonado tiene derecho — según el Código- a una indemnización o a una pensión alimenticia. ¿Son excluyentes ambos conceptos? ¿Acaso cumplen la misma finalidad?

Respecto de la indemnización, la escasa doctrina es bastante concisa. Mientras Cornejo no dice nada, Plácido (2002) señala que "tal reparación se ordena como consecuencia de la frustración del proyecto de vida, la aflicción de sentimientos, etc." (pp. 389 -399) El Prof. Plácido encuentra como fundamento de dicha indemnización la mitigación del daño a la persona o del daño moral, aunque por cierto, en un trabajo reciente, amplía el elenco de los daños resarcibles.

Creo que la norma va más allá. En efecto, la disolución por ruptura unilateral — sin perjuicio de la liquidación de la comunidad de bienes- no solo causa perjuicios personales o morales. También puede causar daños de orden material.

El problema que suscita la norma tiene que ver con la disyuntiva con la que se sancionan los derechos ya sea a una pensión alimenticia o bien a una indemnización, independientemente de las reglas sobre la liquidación de la denominada sociedad o comunidad de bienes, que, por cierto, puede tener algún nivel de gravitación. 
En efecto, si consideramos que la alternativa planteada por la norma implica que el juez debe conceder una u otra cosa, olvidamos que la pensión alimenticia y la indemnización tienen naturaleza jurídica diferente y cumplen funciones del todo distintas. La primera tiene como fin asistir al abandonado por las posibles carencias que enfrentará cuando el conviviente se aparte del hogar y prive al primero de los medios para su subsistencia. La segunda, por el contrario, apunta a reparar el daño, personal o eventualmente patrimonial, producto de la decisión de dar por concluida la relación convivencial que, sin duda, puede tener efectos sobre las emociones, sobre la autoestima y sobre los proyectos de vida construidos a lo largo de la vida compartida en el tiempo.

Con relación a la pensión alimenticia, explica Cornejo (1999) que esa no fue la propuesta que formuló como miembro de la Comisión Reformadora del Código Civil de 1936, pues la concesión de tal pensión le parecía excesiva porque implicaba una modificación del artículo 474 del Código que (según el mismo Cornejo) iba más allá de la Constitución y consolidaba una forma de vida que, para él, no es merecedora de estímulo (pp. 72-73). En rigor, el derecho a una pensión alimenticia en caso de abandono fue introducido por la Comisión Revisora (que estudió las propuestas de la Comisión Reformadora).

Sobre el particular, Bigio (1984), que integró la Comisión Revisora, comenta que:

Durante los debates de esta parte del numeral, el doctor Carlos Montoya Anguerri, entonces vocal de la Corte Superior de Lima, propuso a dicha Comisión que el derecho a pedir alimentos no solo debía ser exigible entre personas que tuvieran vínculo de parentesco o de familia. Montoya expresó que consideraba justo que si se reconocía derechos sobre los bienes comunes a quienes habían vivido como marido y mujer sin estar casados, con mayor razón se debía, en caso de abandono, conceder el derecho a alimentos. Además, señaló que el derecho a pedir alimentos tiene una vía expeditiva mucho más rápida que la acción indemnizatoria y otorga al interesado una asignación provisional de alimentos. Bigio apoyó la propuesta dada la frecuencia del concubinato en el país. Otro miembro de la Comisión Revisora, el doctor Haya de la Torre, manifestó que, en muchos casos, la pensión alimentaria podía ser más justa y necesaria que una indemnización, que, por recibirse una sola vez, podía ser administrada de forma inapropiada por el interesado (p. 161).

La exposición que relata Bigio da a entender que la pensión fue acogida como una alternativa por razones de celeridad procesal y de una presunta dilapidación de la suma que se recibiere como reparación. Si bien se trataba de una interesante tutela de urgencia, ello no debió cerrar la puerta a una complementaria indemnización en caso de que el abandonado acreditase daños derivados de la ruptura causada por quien se marchó del hogar.

Las discusiones y decisiones de la Comisión Revisora, sin embargo, causaron mayor confusión sobre el derecho a los alimentos entre los miembros de una pareja de hecho dado que se intercambiaron los roles de dos mecanismos de tutela de funciones diferentes. La pensión alimenticia tiene una fundamentación muy diversa a la reparación de daños. Empecemos por decir que, cuando se termina la unión de hecho que motiva el abandono, los afectos concluyeron, pero eso no inhibe ni deja de hacer exigible un mínimo deber de asistencia de quien deja el hogar. Empero, el juez deberá valerse de argumentos concretos, puntuales, sólidos, que superen la dimensión moral del deber de solidaridad, basándose, al efecto, de la comprobación de las reales necesidades del abandonado y de la capacidad económica del concubino que puso fin a la unión.

Pero el tema no queda allí. ¿Cuánto tiempo va a ser exigible esa pensión alimenticia entre convivientes? Recordemos que el primer párrafo del artículo 350 del Código Civil establece que, por el divorcio, cesa la obligación alimenticia entre marido y mujer. Sin embargo, el segundo párrafo de esta norma prescribe que, si el divorcio se declara por culpa de uno de los cónyuges y el otro 
careciere de bienes o de gananciales suficientes o estuviere imposibilitado de trabajar o de subvenir a sus necesidades por otro medio, el juez le asignará una pensión alimenticia no mayor de la tercera parte del culpable. ¿Qué solución debemos observar para el caso del concubinato?

Con la sentencia del 26 de setiembre de 2002 (en la Casación 1.637-2002), la Corte Suprema adoptó una posición poco elaborada. Con dicha ejecutoria, el máximo Tribunal resolvió que el concubino abandonado por decisión unilateral tiene derecho a alimentos, pero que, cuando uno de ellos contrae matrimonio, cualquiere que fuere, incluso el abandonante, cesa dicha obligación alimentaria, dado que el Supremo Colegio entiende que el deber de asistencia solo es exigible en tanto ambos (ex) convivientes no tengan impedimento matrimonial. Con esta decisión, la Corte Suprema ha desconocido la función que cumplen los alimentos y ha consagrado una salida de escape al deudor alimentario, lo que deja en el desamparo al abandonado bajo un argumento reñido con lo que dice la propia norma, dado que la ausencia de impedimento solo aplica cuando la convivencia pervive.

En nuestra opinión, los alimentos deben prestarse mientras el abandonado carezca de medios para subsistir sin importar si el conviviente que se alejó de la vivienda común contrajo matrimonio o no. Otra cosa será discutir el quantum frente a las nuevas obligaciones asumidas por el exconviviente que celebró nupcias con un tercero (Espinoza, 2002, p. 8).

Es fácil advertir que, para condenar al abandonante al pago de una pensión, seguimos razonando en términos de culpabilidad, pero ello no oculta las reales necesidades del abandonado. Por ende, creo que, para determinar el monto y la propia duración de la pensión en el tiempo, es útil recurrir al artículo 350 del Código Civil.

Artículo 350.- Por el divorcio cesa la obligación alimenticia entre marido y mujer.

Si se declara el divorcio por culpa de uno de los cónyuges y el otro careciere de bienes propios o de gananciales suficientes o estuviere imposibilitado de trabajar o de subvenir a sus necesidades por otro medio, el juez le asignará una pensión alimenticia no mayor de la tercera parte de la renta de aquél.

El excónyuge puede, por causas graves, pedir la capitalización de la pensión alimenticia y la entrega del capital correspondiente.

El indigente debe ser socorrido por su ex-cónyuge aunque hubiese dado motivos para el divorcio. Las obligaciones a que se refiere este artículo cesan automáticamente si el alimentista contrae nuevas nupcias. Cuando desaparece el estado de necesidad, el obligado puede demandar la exoneración y, en su caso, el reembolso.

Si el abandonado no acredita ninguna de las situaciones referidas en el numeral 350, la pensión debería ser simbólica y muy limitada en el tiempo o no tener ninguna pensión. Si las acredita, pero el obligado demuestra que el beneficiario de la pensión ya no la requiere, se debe ordenar la extinción de la obligación sin la posibilidad de que se active de nuevo. Es conveniente recurrir, en este caso, al primer párrafo del artículo 483 del Código Civil. Y ello es así con mayor razón en la medida que no estamos ante cónyuges sino ante exconvivientes.

Artículo 483.- El obligado a prestar alimentos puede pedir que se le exonere si disminuyen sus ingresos, de modo que no pueda atenderla sin poner en peligro su propia subsistencia, o si ha desaparecido en el alimentista el estado de necesidad.

Tratándose de hijos menores, a quienes el padre o la madre estuviese pasando una pensión alimenticia por resolución judicial, esta deja de regir al llegar aquéllos a la mayoría de edad. Sin embargo, si subsiste el estado de necesidad por causas de incapacidad física o mental debidamente comprobadas o el alimentista está siguiendo una profesión u oficio exitosamente, puede pedir que la obligación continúe vigente 
También debe extinguirse la obligación cuando el exconcubino abandonado contrae nupcias o mantiene una nueva relación de hecho, pues será el nuevo consorte quien deberá asumir tal deber (Placido, 2002, pp. 399-400). Distinta solución se podrá obtener si quien se casa o forma un nuevo hogar convivencial es quien abandonó a su anterior compañero (a), pues, si el abandonado todavía requiere de asistencia, la obligación perseguirá al antiguo concubino, lo que puede afectar la sociedad de gananciales que tenga el abandonante con terceros o sus bienes propios si optó por el régimen de separación de patrimonios (Plácido, 2002, p. 400).

A su turno, la indemnización derivada del abandono no puede tener como objeto garantizar de por vida la colmación de las necesidades del abandonado. Si este obtiene ingresos o contrae matrimonio de modo que pueda ver atendidos sus requerimientos, los daños que pudiere haber sufrido no desaparecerán ni merecen ser perdonados al abandonante. Ello es algo que parece haber olvidado la Comisión Revisora.

La indemnización, por otro lado, quizá podría reemplazar o hacer innecesaria la pensión alimenticia si aquella se extendiese a conceptos indemnizables diversos a los daños (generalmente morales) que padece el conviviente abandonado. Y aquí me quiero servir de la llamada indemnización compensatoria de la legislación española, tanto del Código Civil hispano para los matrimonios como de la legislación autonómica de Cataluña sobre parejas estables. ${ }^{3}$ También existe esta figura en otras legislaciones.

La ley catalana de 1998 establece una interesante compensación económica al término de la convivencia a favor de aquel que, sin retribución o con retribución insuficiente, haya trabajado para el hogar común o para el otro conviviente, cuyo fin es atender una eventual situación de desigualdad entre el patrimonio de los dos miembros de la pareja que implique un enriquecimiento injusto y, además (creo), para poder subvenir los requerimientos de quien carece de una fuente de ingresos. La idea me parece fascinante debido a que no siempre, al momento de liquidar la comunidad de bienes, los jueces considerarán que la dedicación de uno de los cónyuges al hogar le significará una pérdida de oportunidades que podría tener consecuencias negativas al momento en que el abandonado ya no cuente con los ingresos de quien aportaba al hogar de hecho. Además, encaja, en mi opinión, con el sentido de que tendría la indemnización a la que se refiere el artículo 326, debido a que, solo en este caso, no se la limitaría a la simple reparación del daño personal o del daño moral, sino que, asimismo, englobaría el deber de asistencia, pero siempre dentro de la causa del cese de la unión: el abandono, que, curiosamente, no es el supuesto de las leyes españolas antes referidas y que se refiere al cese en general.

Si fuera necesario recurrir a la legislación nacional para buscar alguna apoyatura, entendería que la modificación del régimen del divorcio para introducir la disolución del vínculo por mediar separación de hecho (inciso 12 del artículo 333 del Código Civil) introdujo una interesante vía de exploración.

En efecto, además de que quien invoque la separación de hecho debe encontrarse al día en el cumplimiento de sus obligaciones alimentarias $u$ otras que hubieren sido pactadas de común acuerdo por los cónyuges y del deber del juez de velar por la estabilidad económica del cónyuge e hijos que resulten perjudicados por dicha separación, el artículo 345-A establece, como una obligación del juez, el señalar una indemnización por daños, incluido el daño personal, u ordenar la adjudicación preferente de bienes de la sociedad conyugal, independientemente de la pensión alimenticia que le pudiere corresponder.

En otras palabras, y aunque restringida erróneamente por el legislador al supuesto de la separación de hecho (pues debió ser aplicable a todo cese no convencional) la norma apenas

Sobre la cual puede verse ZAMBRANO, Virginia, Parejas no casadas e tutela del conviviente. L'esperienza spagnola e la Llei Catalana 10/1998,. En Matrimonio, matrimonii. A cura di Francesca Brunetta d'Usseaux y Antonino D'Angelo.

Milano: Giuffré, 2000, pp. 393 y ss.; 
aludida diferencia claramente entre la indemnización de daños, que se pagaría con una suma capital (ya sea el daño personal o bien el patrimonial, o ambos) o con una separación no proporcionada de los bienes gananciales (para reparar el daño patrimonial), y la pensión alimenticia, que tiene como fin garantizar la subsistencia del mismo cónyuge que es indemnizado.

La misma lógica podría al momento de interpretar y aplicar el artículo 326 del Código para la unión de hecho en el caso de abandono. El conviviente que no decidió la separación debe ser asistido con la pensión alimenticia que asegure su sobrevivencia, pero también se le debe reparar los daños que sufra, ya sea tomando parte mayor de los activos que conforman la comunidad de bienes o bien condenando al abandonante al pago de una suma capital como resarcimiento.

Pero claro, hasta este momento nos hemos ocupado de los alimentos cuando concluye la unión de hecho, ¿y qué ocurre mientras se mantiene estable?

\section{De deber natural a deber de soporte constitucional: una lectura recreativa del Código civil a partir de la Constitución}

Ya el Tribunal Constitucional ha sostenido que sería una interpretación muy constreñida de la Constitución el concebir en una unión de hecho que no exista obligaciones de tipo alimentario 4 . Luego desarrollaremos este punto neurálgico, que es la tesis de este ensayo.

Adicionalmente a ello, en materia laboral, el Decreto Legislativo $N^{\circ} 688$, Ley de Consolidación de Beneficios Sociales, concede al trabajador empleado u obrero el derecho a un seguro de vida a cargo de su empleador, una vez cumplidos cuatro años de trabajo al servicio del mismo. El seguro de vida es de grupo o colectivo y se toma en beneficio del cónyuge o conviviente y de los descendientes (art. 1). Para tal efecto, el art. 16 de dicha Ley señala que, tratándose de las uniones de hecho, la compañía de seguros consignará ante el Juzgado de Paz Letrado el importe del capital asegurado que pueda corresponder al conviviente que figure en la declaración jurada o testamento por escritura pública.

La Ley de Compensación por Tiempo de Servicios, con Texto Único Ordenado aprobado por D.S. $N^{\circ}$ 001-97-TR, en su artículo 39 dispuso que la compensación por tiempo de servicios tiene la calidad de bien común sólo a partir del matrimonio civil, o de haber transcurrido dos años continuos de la unión de hecho.

De acuerdo al artículo 54 de dicha Ley, el depositario de la Compensación, a solicitud de parte, entregará, sin dilación ni responsabilidad alguna al cónyuge supérstite o al conviviente a que se refiere el Artículo 326 del Código Civil, que acredite su calidad de tal, el 50\% del monto total acumulado de la compensación por tiempo de servicios y sus intereses, en caso el trabajador hubiese fallecido.

También las Normas Técnicas del Seguro Complementario de Trabajo de Riesgo, (Decreto Supremo $\mathrm{N}^{\circ}$ 003-98-SA), conceden cobertura al servidor o sus beneficiarios por los riesgos de invalidez o muerte producida como consecuencia de accidente de trabajo o enfermedad profesional, y hace participar como uno de los beneficiarios del trabajador al concubino y le reconoce el derecho a la pensión de viudez y a los gastos de sepelio.

En materia de seguridad social, la Ley de Modernización de la Seguridad Social en Salud, Ley $N^{\circ}$ 26790, considera beneficiario al concubino a que se refiere el artículo 326 del Código Civil, cuando no es afiliado.

La Ley del Sistema Privado de Pensiones, con Texto Único Ordenado aprobado por D.S. № 00498-EF, incluye al conviviente como beneficiario de la pensión de sobrevivencia.

4 Considerando 22 (a modo de obiter dicta) de la sentencia del 6 de noviembre de 2008 (Expediente N 06572-2006-PA/TC). 
A ello se suma la sentencia del Tribunal Constitucional en la causa seguida por doña Janet Rosas Domínguez (Exp. № 06572-2006-PA/TC) del 06 de noviembre de 2007 que reconoció el derecho a la pensión en el sistema previsional público.

En el considerando 13 de esta decisión, el Tribunal, tras precisar que la Constitución de 1979 restringió el tratamiento de la unión de hecho a la llamada sociedad de bienes, señaló que:

3. Pero esta constitucionalización de la entidad también implica el reconocer ciertos efectos jurídicos entre quienes conforman la unión de hecho. Si bien se está ante una institución que se fundamenta en la autonomía de la voluntad de quienes la integran y que en puridad se caracteriza por su informalidad en cuanto a su inicio y su desarrollo, no es menos cierto que el Estado puede intervenir y regular conductas a fin de evitar situaciones no deseadas en la sociedad. Así pues, la Constitución reconoce una realidad, pero al mismo tiempo, la encausa dentro de los valores constitucionales a fin de hacerla compatible con el resto del ordenamiento. En tal sentido, a fin de evitar que el aporte realizado por la pareja durante la convivencia sea apropiado por uno de ellos, en desmedro del otro, la Constitución reconoció expresamente el régimen de gananciales a estas uniones, en cuanto les sea aplicable. Con esto, fenómenos como el comentado se verían refrenados, brindando una dimensión de equidad a las uniones fácticas. Pero esta no sería la única obligación que se generaría entre los convivientes, como observaremos más adelante, la propia dinámica de la convivencia encuadrada en la disposición constitucional implica el cumplimiento de ciertas acciones, por parte de los integrantes de la unión.

Luego, tras revisar lo que sanciona la actual Constitución de 1993, que luego veremos, esto es, el principio de protección de la familia, sin más, al lado del principio de promoción del matrimonio, aseveró que:

21. No obstante, es de resaltar que estos efectos patrimoniales surgen de la comunidad de vida que llevan los convivientes. Esta comunidad debe ser comprendida como la coincidencia de fines, objetivos, modos de apreciar el mundo y expectativas sobre futuro, substrato sobre el cual se erige el aprecio y afecto que se proveen las parejas, precisamente por lo cual, comparten su vida en un "aparente matrimonio." De lo que se infiere que existe también ciertas obligaciones no patrimoniales. Por ejemplo, como ya se observó, la configuración constitucional de esta unión libre genera un deber de fidelidad entre quienes la conforman. (La negrita es mía).

Para añadir luego que:

22. De igual modo, sería una interpretación bastante constreñida de la Constitución el concebir que en una unión de hecho no exista, por ejemplo, obligaciones de cooperación o de tipo alimentaria. Contémplese sino la situación en que uno de los convivientes requiera los auxilios pertinentes del otro por caer enfermo. Más aun, no debe dejarse de observar que frente a la terminación de la unión, por decisión unilateral, la pareja abandonada puede solicitar indemnización o pensión alimenticia [art. 326 CC]. Es decir, frente a la dependencia económica generada, se deben plantear contextos jurídicos que viabilicen y materialicen el sentido material y concreto de la Constitución". (La negrita es mía)

"23. En suma, debe enfatizarse que la unión de hecho genera una dinámica a partir de la cual se originan dependencias entre los convivientes. Por ejemplo, es muy común que se de el caso en donde uno de ellos se ocupe de las labores que exige el hogar, dejando de lado el ámbito laboral, mientras que la pareja, se desarrollará en el espacio profesional, cumpliendo la tarea de brindar los medios económicos que sustenten la vida en comunidad. Esta sinergia incluye pues un deber de asistencia mutua". (La negrita es mía). 
Tras una larga fundamentación con la finalidad de conceder al concubino sobreviviente el derecho a la pensión, el Tribunal hizo referencia al Fundamento 143 de la Sentencia del Expediente 00502004-Al/TC del mismo Colegiado en el que se sostuvo que:

Debe ser concebida como una garantía para velar por el mantenimiento de una vida acorde con el principio de dignidad de aquellos que, en razón de un vínculo familiar directo, dependían económicamente de parte de dicha pensión, es decir, como una garantía derivada del reconocimiento de la familia como instituto fundamental de la sociedad (artículo 4 de la Constitución).

En consecuencia, prima facie, la posibilidad de que el monto o parte del monto de la pensión del causante se materialice en una pensión de sobrevivencia, debe encontrarse condicionada a la dependencia económica en la que se encontraba el o los sobrevivientes con relación a dicho monto" (subrayado agregado).

De la lectura de esta sentencia de la Corte Constitucional se deduce claramente que la unión de hecho es una familia que origina deberes y consecuencias similares a los de una familia basada en el matrimonio.

Tratemos de llegar al punto central de este trabajo.

A diferencia de la Carta de 1979, la actual Constitución incorporó el principio de protección de la familia en su art. 4:

Artículo 4.- La comunidad y el Estado protegen especialmente al niño, al adolescente, a la madre y al anciano en situación de abandono. También protegen a la familia y promueven el matrimonio. Reconocen a estos últimos como institutos naturales y fundamentales de la sociedad.

La forma del matrimonio y las causas de separación y de disolución son reguladas por la ley.

De esa manera, con la actual Constitución la protección de la familia quedó desvinculada de la existencia del matrimonio. ¿Qué implica ello?

Esta norma genera una serie de cambios sustanciales. En primer lugar, no supedita la tutela de la familia a la matrimonial. El manto protector se extiende a todas las familias. Inclusive se pone énfasis en la familia monoparental cuando se alude a la madre en abandono. Ello es inocultable.

Si a ello sumamos que la Constitución tiene valor normativo y que ocupa una posición central en el ordenamiento jurídico (García de Entería, 1985) y a que la Constitución desarrolla una función de irradiación sobre el resto del ordenamiento, un aspecto esencial a tomar en cuenta es el de la interpretación constitucional del orden jurídico que ha de afectar (Balaguer, 1997).

Bajo esta inicial apreciación la regulación de la familia por el Código civil se ve alterada por el principio de protección integral a la familia, incluida la basada en la unión de hecho.

En tanto principio de rango constitucional, el principio de protección de la familia debe ser "informador" del ordenamiento, como usualmente se ha reconocido, pero ello no niega que, a la vez, pueda tener valor normativo dada la multifuncionalidad de los principios y a que su aplicación directa no está descartada para resolver conflictos jurídicos (Balaguer, 1997).

A partir de ello, la consagración del principio de protección de familia en el texto del actual art. 4 de la Constitución debe incidir no solo sobre el Código civil, sino también ser leído y aplicado al momento de interpretar y aplicar el art. 5 de la misma Carta más allá que pueda parecer una repetición no meditada del numeral 9 de la Constitución de 1979 
Y es que no concibo que a la luz del principio de protección ("integral") de la familia, la protección de la unión de hecho permanezca reducida a aspectos patrimoniales.

La lectura constitucional del art. 5 por medio del numeral 4 no altera el texto de la primera de las normas constitucionales en cuestión pero modifica su significado. Se trata, en mi opinión, de una mutación constitucional que es resultado de un proceso de interpretación imperceptible como puede serlo la interpretación considerada desde el punto de vista, más general, de la evolución jurisprudencial en la aplicación del derecho, según sostiene Balaguer (1997, pp. 33-34). Claro está que esa interpretación puede ser propuesta desde la doctrina y se convertirá en una opción válida si la acoge la jurisprudencia. La idea es sumamente atractiva pues se trata de un mismo texto, reinterpretado por una nueva realidad socio-política, que destaca otro sentido de la letra escrita, que responde a una realidad que es mutable (Balaguer, 1997, p. 34).

A partir de estas premisas mantengo una posición diferente a la de mi buen amigo, el destacado Prof. Álex Plácido ${ }^{5}$, cuando sostiene que:

Cabe recordar que, disponiendo la Constitución el reconocimiento de que de la unión de hecho surge una familia que debe ser también objeto de protección constitucional y el mandato de promoción del matrimonio, resulta claro que hoy los efectos legales estructurados sobre la idea de la protección de la familia deben ser reconocidos tanto a aquella que nace de un matrimonio como la que surge de una unión de hecho; debiéndose enfatizar en que los mecanismos legales para acceder a ellos admitidos a favor de los casados, deben ser diferentes a los que corresponden a los convivientes. De acuerdo con ello, el tratamiento y las consecuencias jurídicas de los deberes familiares emergentes de una unión de hecho son diferentes a los del matrimonio. Así, si se analiza el deber de asistencia en su ámbito material, se comprueba que entre los cónyuges existe una obligación legal de alimentos que puede subsistir, excepcionalmente, después de disuelto el vínculo matrimonial. En cambio, en la unión de hecho se presenta una obligación alimentaria similar a la que existe entre los cónyuges; sin embargo, ésta no es legal sino de carácter natural. Este derecho a los alimentos entre convivientes se fundamenta en la preservación del sentimiento familiar que los vincula y que se hace sentir de modo tan evidente en la estructura y funcionamiento de la propia unión de hecho; demostrando, en su naturaleza y esencia, un contenido moral derivado de ese estado de familia. El reconocimiento de la obligación natural de alimentos entre convivientes tiene como consecuencia principal la irrepetibilidad de lo que se ha pagado en cumplimiento de dicha obligación, de acuerdo con el artículo 1275 del Código Civil: "no hay repetición de lo pagado para cumplir deberes morales o de solidaridad social...". De otra parte y si la unión de hecho termina por decisión unilateral, este deber natural se transforma en una obligación legal de prestar alimentos a cargo del abandonante, cuando el abandonado opta por esta pretensión, de acuerdo con el artículo 326 del Código Civil.

Sin dejar de reconocer que el Prof. Plácido ha sido siempre un civilista precursor en sus ensayos que echa mano al Derecho constitucional, esta vez me debo alejar de su opinión. Creo, por el contrario, por los argumentos que he desarrollado, que el deber de asistencia alimentaria entre concubinos no es un deber natural. Por el contrario, es un deber de orden normativo sustentado en la aplicación del principio de protección de la familia que, como anotaba, tiene naturaleza normativa y no solo principista, esto es, es una norma constitucional (de mayor jerarquía que el Código) de aplicación inmediata que tiene como consecuencia soportar el deber de asistencia familiar entre los miembros de la pareja de hecho estable.

Sería un contrasentido sostener que sí existe un derecho a alimentos cuando concluye la unión por abandono unilateral y que en tanto los concubinos conviven no hay espacio para predicar y

5 Plácido, A. (2008) Recuperado de: http://blog.pucp.edu.pe/blog/alexplacido/2008/04/21/el-principio-de-reconocimientointegral-de-las-uniones-de-hecho-segun-el-tribunal-constitucional/ 
exigir el deber de asistencia. Por ello no entiendo la opinión de Álex Plácido cuando señala que un deber moral o natural se convierte en legal solo en ese momento. Quizá a ello pueda replicar que el deber de prestar alimentos entre convivientes no es legal, pero que tiene basamento constitucional.

Sería muy audaz afirmar que los consortes tienen derecho a la pensión de viudez que no es otra cosa que una expresión del deber de socorro que se proyecta en el tiempo cuando uno de los dos convivientes fallece y, por el contrario, aseverar que no existe ese deber (o que es moral) cuando ambos viven y permanecen juntos como pareja estable.

Y no intento utilizar un canon de interpretación particular (contrario sensu) para llegar a tales conclusiones, pues las Cortes podrían haber echado mano al mismo sin mayores contratiempos. Creo, por el contrario, que Jueces y Tribunales han profesado demasiado respeto al texto de la ley (al texto del Código civil) en cuanto no incluye a los concubinos dentro de los sujetos obligados a la asistencia alimentaria sin releer a través del prisma constitucional estas reglas con la finalidad de hacer realidad un principio de rango supremo como lo es el de la protección de la familia.

El connotado jurista chileno Corral (2014), al analizar las relaciones derivadas de la supremacía de la Constitución en la era del neoconstitucionalismo, alude a tres formas en las que opera la constitucionalización del Derecho civil:

(i) la reforma legal motivada por la Constitución para adecuar las leyes a los principios constitucionales; (ii) la vía hermenéutica o de aplicación indirecta que no es otra cosa que la conocida "interpretación conforme a la Constitución" que no se reduce a una simple relectura; por el contrario es una actuación de los principios de la Constitución desde el interior mismo del sistema de modo que las reglas del Código sean vehículo de actuación de aquellos valores y; (iii) la vía de la aplicación directa, que no solo opera cuando no existe una norma de orden legal cuya espera no se tolera, sino también cuando existe una ley ante cuya solución la Constitución quiere ofrecer una protección alternativa. En el extremo podría recurrirse a una aplicación directa contra legem cuando se prefiere los criterios de la norma constitucional.

En mi opinión, al hacer uso de este mecanismo de constitucionalización del Derecho civil contaremos con las herramientas necesarias para poder entender que la protección de la familia, incluida la concubinaria, nos debe permitir aseverar, con fundamento de orden constitucional, que los miembros de una pareja de hecho estable cumplen deberes similares a los de la familia matrimonial, especialmente el de asistencia que involucra, entre otros, el deber alimentario.

Si ello es así, entonces no queda sino entender que el art. 474 del Código civil se ha convertido en una norma que se estrella contra un principio constitucional y que, aunque pueda ser extremo, su lectura y aplicación debe ceñirse al mandato constitucional aun cuando dicho principio se aplique contra legem.

\section{REFERENCIAS BIBLIOGRÁFICAS}

ARIAS SCHREIBER, M., ARIAS SCHREIBER, A. y PLÁCIDO, A. (2002)., Exégesis del Código civil peruano de 1984, Tomo VII, Derecho de Familia, Lima: Gaceta Jurídica.

Asamblea Constituyente. (1978-1979) Diario de Debates de la Comisión Principal de Constitución de la Asamblea Constituyente. Lima, Publicación Oficial, Tomo I.

CORRAL TALCIANI, H. (2014). Constitucionalización del Derecho Civil. Reflexiones desde el sistema jurídico chileno, en Derecho Civil Constitucional, Instituto de Ciencias Jurídicas de Puebla. Puebla: Grupo Editorial Mariel S.C., Universidad de la Sabana. pp. 8 ss.

Balaguer, M. (1997). Interpretación de la Constitución y del ordenamiento jurídico. Madrid: Tecnos. 
BIGIO, J. (1992). El concubinato en el Código civil de 1984, en Libro Homenaje a Carlos Rodríguez Pastor, Lima: Cultural Cuzco.

CORNEJO CHÁVEZ, H. (1999). Derecho familiar peruano. Lima: Gaceta Jurídica

ESPINOZA, J. (julio 2002). La necesaria parificación constitucional entre la unión de hecho y el matrimonio. Legal Express. Año 2, N 19, Lima. p. 8.

GARCÍA DE ENTERRÍA, E. (1985). La Constitución como norma y el Tribunal Constitucional, Madrid: Civitas, Madrid. p. 49.

PLÁCIDO, A. (2002). Regímenes patrimoniales del matrimonio y de las uniones de hecho, Lima, Gaceta Jurídica. pp. 398-399.

VEGA, Y. (2005), Las nuevas fronteras del Derecho de Familia. (2da edición) La Libertad: Colegio de Abogados de La Libertad.

Fecha de recepción: 14 de setiembre de 2018

Fecha de aceptación: 30 de octubre de 2018 